The Global Health Network Collections • Breastfeeding and Breast Milk - from Biochemistry to Impact, (Ed, Family Larson- Rosenquist Foundation) Georg Thieme Verlag KG

\title{
10 Breastfeeding \\ Promotion: Politics and Policy
}

Ashley M. Fox, PhD, MA

Published on: May 01, 2020

DOI: $10.21428 / 3 d 48 c 34 a . b b 0474 d e$ 


\section{Breastfeeding Promotion: Politics and Policy}

Ashley M. Fox, PhD, MA

\section{Expected Key Learning Outcomes}

- The key political discussion points in relation to breastfeeding

- The main women's rights issues facing mothers wishing to breastfeed

- How focusing on the rights of the child can have a negative impact

- The effect human rights campaign has had on breastfeeding

- The political actions that could support breastfeeding promotion

\subsection{Introduction}

To assess the barriers to more widespread adoption of breastfeeding promotion policies internationally, this chapter approaches the issue of human lactation from a political perspective. Research has shown the benefits to infant survival of early and sustained breastfeeding, particularly in low- and middle-income countries (LMIC), as well as sustained benefits throughout the life cycle. UNICEF has boldly declared that 'breastfeeding saves more lives than any other preventive intervention' and the World Health Organization (WHO) recommends exclusive breastfeeding for the first six months of life. In spite of the purported health benefits of breastfeeding, policies that protect and promote breastfeeding vary widely across countries and breastfeeding promotion efforts face a number of obstacles.

This chapter reviews the literature on breastfeeding politics and policy. The paper suggests that breastfeeding promotion policies have not been more widely adopted because of the different ways in which breastfeeding has been framed, and its degree of contentiousness, at specific time points in its history. Drawing on Stone's concept of "causal stories", the chapter argues that the success of breastfeeding advocacy groups at raising attention to breastfeeding will hinge on the way the problem is framed, successful identification of "villains", and matching of solutions to the problem. As Stone [1] tells us: 
'Problem definition is a process of image making, where the images have to do fundamentally with attributing cause, blame, and responsibility. Conditions, difficulties, or issues thus do not have inherent properties that make them more or less likely to be seen as problems or to be expanded. Rather, political actors deliberately portray them in ways calculated to gain support for their side. And political actors, in turn, do not simply accept causal models that are given from science or popular culture or any other source. They compose stories that describe harms and difficulties, attribute them to actions of other individuals or organizations, and thereby claim the right to invoke government power to stop the harm.'

The chapter identifies three primary causal stories that have been used to frame breastfeeding as a problem; each causal story describes different primary causes of the problem, which imply different potential policy solutions. These include framing the problem from the angles of "women's rights", "children's rights", and "global human rights". Breastfeeding promotion has passed through several "frame contests" (i.e., contested understandings of the nature of the problem) that have at times advanced the issue dramatically, and at other times led to conflict. It is important to understand these different frames because knowing what factors draw attention to an issue, and which factors make the issue contentious and less attractive, can influence the degree of traction the issue receives from governments and the success of breastfeeding promotion activities. These frames each place blame, cause, and responsibility on different actors (including the so called villains - Table 10.1). When framed as a women's rights issue, gender inequality, patriarchal culture, and prudish Western attitudes towards breasts and women's bodies become the principle source of contention. Breastfeeding advocates look to work-related policies and protection in public spaces to normalise the act of breastfeeding and link it more broadly to gender equality and equal participation in society.

By contrast, in the children's rights frame, mothers who choose to work or to bottle feed rather than breastfeed for reasons of convenience are considered the principle reason for low breastfeeding rates. Thus, efforts are targeted at making replacement feeding less convenient and harder to accomplish by policies that include prescriptions for formula, and restricting the point of sale and advertising of formula.

\section{Tab.10.1 Summary of characteristics of different breastfeeding issue frames}

Issue frame

Villain
Causal story
Policy solutions

Tensions/trade-offs 


\begin{tabular}{|c|c|c|c|c|}
\hline Women's Rights & $\begin{array}{l}\text { Patriarchal/ } \\
\text { puritanical/ male- } \\
\text { dominant culture }\end{array}$ & $\begin{array}{l}\text { Women would } \\
\text { breastfeed more but } \\
\text { maledominant, } \\
\text { corporate culture } \\
\text { restricts their ability } \\
\text { to do so; women's } \\
\text { breasts have been } \\
\text { sexualised; } \\
\text { breastfeeding } \\
\text { represents a woman's } \\
\text { re-appropriation of } \\
\text { her body }\end{array}$ & $\begin{array}{l}\text { Work-related policies } \\
\text { (e.g., paid maternity } \\
\text { leave, flex time, } \\
\text { pumping breaks); } \\
\text { reform of indecency } \\
\text { laws and the creation } \\
\text { of a supportive } \\
\text { culture and } \\
\text { environment for } \\
\text { breastfeeding; re- } \\
\text { normalise } \\
\text { breastfeeding }\end{array}$ & $\begin{array}{l}\text { Women may not } \\
\text { want to take time off } \\
\text { to breastfeed; } \\
\text { breastfeeding } \\
\text { reinforces gendered } \\
\text { division of labour; it } \\
\text { assumes all women } \\
\text { have equal choice }\end{array}$ \\
\hline Children's Rights & $\begin{array}{l}\text { Mothers who do not } \\
\text { breastfeed }\end{array}$ & $\begin{array}{l}\text { Women choose to } \\
\text { work for } \\
\text { "convenience" rather } \\
\text { than to breastfeed; } \\
\text { women may } \\
\text { underestimate their } \\
\text { ability to breastfeed }\end{array}$ & $\begin{array}{l}\text { Fear-factor approach, } \\
\text { i.e., scare women } \\
\text { into breastfeeding; } \\
\text { exaggerate research } \\
\text { claims; promote } \\
\text { breastfeeding in } \\
\text { hospitals; limit access } \\
\text { to feeding } \\
\text { alternatives }\end{array}$ & $\begin{array}{l}\text { Privilege the child's } \\
\text { welfare over the } \\
\text { mothers; use of } \\
\text { shame and fear to } \\
\text { motivate action; } \\
\text { research on the } \\
\text { benefits of breast vs } \\
\text { bottle is weak, and is } \\
\text { based more on } \\
\text { ideology and cultural } \\
\text { assumptions than on } \\
\text { solid evidence }\end{array}$ \\
\hline
\end{tabular}




\begin{tabular}{|c|c|c|c|c|}
\hline Global Human & $\begin{array}{l}\text { "Greedy" } \\
\text { transnational } \\
\text { formula companies }\end{array}$ & $\begin{array}{l}\text { Under the guise of } \\
\text { helping women that } \\
\text { cannot breastfeed } \\
\text { and their babies, } \\
\text { greedy transnational } \\
\text { companies spread } \\
\text { their "lethal" wares } \\
\text { (formula) on } \\
\text { unsuspecting } \\
\text { mothers. They are } \\
\text { directly responsible } \\
\text { for millions of deaths } \\
\text { globally that result } \\
\text { from unsafe use of } \\
\text { replacement feeding }\end{array}$ & $\begin{array}{l}\text { Global Policy } \\
\text { Agreements (e.g., } \\
\text { International Code on } \\
\text { the Marketing of } \\
\text { Breast Milk } \\
\text { Substitutes); } \\
\text { Innocenti } \\
\text { Declaration; Baby- } \\
\text { Friendly Hospital } \\
\text { Initiative }\end{array}$ & $\begin{array}{l}\text { Ignores the } \\
\text { underlying problem } \\
\text { of lack of clean water } \\
\text { and sanitation but } \\
\text { instead scapegoats } \\
\text { formula companies; } \\
\text { glosses over the } \\
\text { reality that women in } \\
\text { LMICs may also } \\
\text { experience trouble } \\
\text { breastfeeding and } \\
\text { that low rates of } \\
\text { exclusive } \\
\text { breastfeeding may be } \\
\text { due to causes other } \\
\text { than formula; } \\
\text { neglects the } \\
\text { difference between } \\
\text { urban, affluent } \\
\text { women (whose risks } \\
\text { are closer to those in } \\
\text { the global North) and } \\
\text { poor, illiterate, rural } \\
\text { women; creates a } \\
\text { double standard, i.e., } \\
\text { the risk to babies in } \\
\text { HICs is not } \\
\text { equivalent to the } \\
\text { risks to babies in } \\
\text { LMiCs }\end{array}$ \\
\hline
\end{tabular}

HIC $=$ high-income countries; LMIC = low - and middle-income countries

In the global human rights frame, "third world" women are depicted simultaneously as "good" mothers for their relatively higher breastfeeding rates and as "victims" of greedy transnational corporations seeking profit at the expense of the health and wellbeing of infants. Policies to promote breastfeeding in this context include limiting the availability of substitute feeding, implementation of "baby-friendly" hospitals, and development of the International Code of Marketing of Breastmilk Substitutes. However, this framing of the problem may not be sufficiently attentive to the needs of women in LMICs. For these women, replacement feeding is not merely a question of convenience or autonomy. It may be a matter of life and death for their infants due to conditions of extreme poverty. 
Wider attention to policies that confront these conditions of poverty and adapt pro-breastfeeding messages to the social context may be warranted.

Across all three frames, the corporate villain is an easy and ready target, putting profit above the health and welfare of mothers and babies, and aligns these three perspectives. The marketing, advertising, and promotion of formula are targeted as a convenient scapegoat. However, this villain identification may also gloss over important differences in the problem definition and policy responses between high and low income settings. This chapter provides a critical viewpoint on these three frames - women's rights, children's rights, and global human rights. It suggests that the breastfeeding advocacy movement adopt more of a "harm reduction" approach to breastfeeding, balancing the benefits of exclusive breastfeeding against the real-life challenges of breastfeeding that make bottlefeeding appealing and sometimes necessary.

\subsection{The Three Frames of Breastfeeding Politics}

\subsubsection{Breastfeeding as a Women's Rights Issue}

When framed as a women's rights issue, gender inequality, patriarchal culture, and prudish Western attitudes towards breasts and women's bodies become the principle arguments around breastfeeding. Radical feminist thinking has embraced breastfeeding, and considers it as a means of reappropriating and desexualising women's breasts, representing women's rights to control their bodies (Attar, 1988, cited in Carter 1995 [2]]). Van Esterik's tome on breastfeeding of 1989 [3] ] embraces this framing. She refers to notions of "mother power" in reclaiming natural womanhood of which women have been deprived as the cultural context has shifted towards greater acceptance of bottle over breast. Likewise, Marxist feminists have focused attention on the ways in which capitalist development has led to commercialisation of breast milk products that devalue natural products like mother's milk. Changing production modes have contributed to the devaluation of women's unpaid work within the home (including child care responsibilities and breastfeeding) as compared with paid work in the private sphere. Breastfeeding has thereby come into conflict with male-dominant workplace environments with little work-life flexibility or private space for women to express milk. To gain acceptance and equality in the workplace, and to keep up with the declining value of men's paychecks, women are increasingly torn between employed work and family demands while workplace policies have not evolved to meet this new reality [4]. 
This framing views breastfeeding politics as an expression of women's empowerment and breastfeeding promotion policies. Such politics are essential to giving women choices over how to use their bodies, with milk substitutes providing an "illusion of liberation" only []ㅡ. For breastfeeding rights activists, or "lactivists", breastfeeding represents a protest against a culture that is friendly towards bottle feeding and hostile towards breastfeeding; it also represents a reclaiming of public spaces to make them less hostile towards infant feeding [6]. According to Hausman [7], lactivist feminists tend to see a culture that favours infant formula and is beset by barriers to breastfeeding, be it in homes, workplaces, or in public spaces where the women's right to feed their infants is frowned upon [ㅁ] $]$.

Moreover, in this framing of the problem, mothers making decisions about infant feeding or breastfeeding their newborns are faced with dissonant messages. On the one hand, they recognise the medical benefits to breastfeeding and desire the opportunity to provide this benefit to their infants but, simultaneously, face the reality of social structures that erect barriers to its practice. The choice to breastfeed is in this frame may therefore be viewed as a form of protest that seeks to redefine women's bodies and the lines between public and private spaces.

Though often treated as separate from the natural childbirth and "back to nature" movements, the choice to breastfeed can similarly be viewed as a rejection of the medicalisation of childbirth [2]. The women's liberation movement encouraged women to gain knowledge and power, and avoid unnecessary childbirth interventions. Resistance to formula feeding by lactivists has also been seen as a means to avoid unnecessary medicalisation of their infants and thereby reclaim breasts for their "primary" physiological function (as opposed to their secondary function as sexual objects) [2].

The "breastfeeding as a woman's right" frame also points to the benefits of breastfeeding not only for the baby, but for the mother. Breastfeeding advocacy movements employ a series of instrumental arguments to convey breastfeeding benefits for both infants and mothers. For example, such benefits include weight loss, uterus contraction for faster postpartum recovery, cost-effectiveness, promotion of infant bonding, and a possible risk reduction for breast and cervical cancer. (See, e.g., WebMD's description of the benefits of breastfeeding for women: http://www.webmd.com/parenting/baby/nursing-basics). Breastfeeding is also framed in some circles as a form of activism against a bottle-dominant, capitalist, convenience culture. In short, in this framing of the issue, breastfeeding is consistent with, and can be used to elevate and advance, women's autonomy

The women's rights frame blames a male-dominant, patriarchal culture that sexualises women's breasts, and the insufficient action by governments to promote and normalise breastfeeding. The causal story views declining breastfeeding rates as emanating from effective marketing campaigns, workplace norms that lack accommodation for breastfeeding mothers, and cultural ambivalence about 
maternal bodies [7]. The locus of blame in this framing is on the government and their complicity in failing to bring the state's regulatory framework to take action, such as compelling employers to offer maternity leave and provide private space for breast milk expression, and reform public decency codes to create areas for breastfeeding.

Available solutions therefore focus on efforts to provide breastfeeding-friendly public spaces, workplace accommodation for pumping, paid maternity leave, and subsidies for breast pumps. Each of these solutions are considered to advance women's rights and autonomy, and foster an environment that goes beyond equality and include women's "capabilities" to breastfeed [9]. Cook (2015) argues against a women's "right to breastfeed", noting that legal rights alone may be inadequate to counteract cultural attitudes against breastfeeding without an understanding of the lived experience of breastfeeding mothers. She argues instead in favour of a liberal "capabilities" approach, drawing on the work of Martha Nussbaum.

\subsubsection{Breastfeeding as a Children's Rights Issue}

A second framing of breastfeeding focusses on the baby. This framing is often written from the perspective of the medical community and organisations dedicated to improving child health such as UNICEF. It emphasises the health benefits of breastfeeding for infants and children throughout the life span. Policy actors operating in this frame build their case for breastfeeding on literature reciting the purported health benefits associated with breast over bottle feeding. These include the prevention of dermatitis, allergies, sudden infant death syndrome, respiratory illnesses, malnutrition, colic, eczema, Crohn's disease, and asthma, and general strengthening of the immune system (thus reducing, for example, ear infections). Mothers who breastfeed will allegedly have more intelligent children than mothers who bottle feed, and exclusively breastfed infants may benefit from lower rates of future obesity and diabetes. These claims can be found in various official documents on infant feeding, for example: UNICEF (2011a, 2011b) [23], [24]; UK NHS (2011a, 2011b) [25], [26]; Stockholm Health Care Guide (2011a, 2011b) [27], [11]; La Leche League (2006) [28] and are more closely scrutinized by a set of critical literature presented later in the chapter.

Evidence for the superiority of breast milk over bottle feeding also relies on "naturalising" breastfeeding. According to proponents of the children's rights frame, breastfeeding fulfils nature's intended purpose for the female breast, providing the perfect food that 'emanates on demand from the breast and is continuously changing to meet the exact needs of both mother and child' [1이]. By contrast, proponents of the children's rights frame denaturalize "artificial" bottle feeding as 'giving a child a processed fluid through a piece of rubber' [1이]. 
The benefits of breastfeeding for the child identified in the biomedical literature have been distilled into official state policy at both national and global levels. The WHO and UNICEF promote breastfeeding, declaring that 'exclusive breastfeeding for 6 months is the optimal way of feeding infants', and that 'thereafter infants should receive complementary foods with continued breastfeeding up to 2 years of age or beyond'. (See WHO website on Exclusive Breastfeeding: http://www. who.int/nutrition/topics/exclusive breastfeeding/en/). Moreover, to enable mothers to achieve this goal, WHO and UNICEF recommend 'breastfeeding on demand - that is as often as the child wants, day and night', and 'no use of bottles, teats or pacifiers'. The 'Breast is Best' slogan is a social marketing tool that has been used to promote breastfeeding in the USA and the UK. The official Swedish policy is that breastfeeding is the best option for babies and that formula should only be given if there is a problem [11]. Packages of formula in the Netherlands are required to carry a message that 'breastfeeding is the best for your baby' [ㅌ1].

In this framing, mother's needs and constraints are secondary to that of the child's. Breastfeeding has declined because women have prioritised convenience, work, or "household orderliness" over the maternal-child dyad. For instance, in early La Leche League publications, The League's advocacy of breastfeeding was full of advice about why household orderliness was less significant than meeting children's needs. J. Law remarks upon a Chicago-area bumper sticker that advertised 'affordable healthcare begins with breastfeeding' [13]. The statement suggests that a woman's decision to breastfeed has implications well beyond her own infant's health, and more broadly attributes blame for wider societal issues including rising health care costs to non-breastfeeding mothers. In this framing, mothers' decision to breastfeed becomes transformed from an individual decision to a civic duty, responsible for ensuring not just the health of individual infants but the health of the next generation [14].

Solutions that address breastfeeding as a children's rights issue include policies that prioritise the rights of the child, such as laws banning pacifiers, prohibiting the advertising and distribution of breast milk substitutes, and incentivising babyfriendly hospitals. There have even been discussions about whether breastfeeding may be considered as part of children's civil rights, which could lead to putative actions against mothers who fail to breastfeed [2]. As expressed in the following post in the Wall Street Journal by Erica Jong (2010), 'mandatory breast-feeding isn't imminent, but it's not hard to imagine that the 'food police' might become something more than a punch line about overreaching government. Mothers, after all, are easy scapegoats' (cited in Hausman 2013 [?]). The ever-changing recommendations about what women should and should not eat and drink while breastfeeding, along with other disputed activities like hair dying, are additional examples of how the children's rights framing places the locus of control and blame on the shoulders of mothers and focusses attention on the impact of their actions on infants. 
In this regard, the children's rights framing and protection policy that it implies may conflict with the promotion of women's autonomy, since such policies may inconvenience working mothers and work against women's equal participation in society. Moreover, a focus on the mother as the central "actor/villain" in this policy narrative tends to individualise the problem, distracting from the broader structures that result in declining breastfeeding rates.

\subsubsection{Breastfeeding as a Global Social Justice Issue}

A third framing of the problem has focused attention on the contribution of bottle feeding to infant mortality in LMICs. The blame in this frame has been placed on the global formula industry, epitomised by the Swiss-based Nestlé corporation, which came to be the focus of a global boycott. To increase profits after saturating markets in developed countries post World War II, infant formula companies began to expand their products into developing countries, where the goal was to make bottle feeding the norm there as well [1ㅇ].

To sell their products to this new consumer base, formula companies turned to colonial imagery, portraying bottle feeding as "modern", and breastfeeding as "primitive" and associated with peasant life [1ㅇ]. In addition to direct advertising, radio spread the word to the illiterate while doctors and hospitals were bombarded with free samples and gifts. Formula companies also utilised "milk nurses", i.e., trained nurses employed by the infant food industries to visit new mothers to sell formula. By associating medical authority with bottle feeding, these practices further contributed to the "medicalisation of formula" or to the idea that it was superior to breast milk for child health. The fact that formula is used for infants with low birth weight who are too weak to suckle only further reinforced the image of infant formula as having medicinal qualities.

Soon after formula sales started to increase, a new "disease" emerged in many low-income countries known as "bottle-baby disease". This encompassed the rapid onset of diarrhoea, dehydration, and malnutrition, resulting from exposure to water- and food-borne pathogens from unsafe water and poor hygiene, respectively. Rates of infant mortality were already high in developing countries, primarily due to these same causes, and breastfeeding practices that had sheltered many newborns from exposure to these pathogens were declining as replacement feeding caught on.

Throughout the 1970s, the international health community, including physicians in developing countries, became increasingly concerned about these marketing practices. They eventually launched one of the most successful global social movements in history against the practices of formula companies. A key tactic of this anti-formula social movement, initiated in 1977 by the US based Infant Formula Action Coalition (INFACT), was to expose the practices of formula companies and equate their 
actions (in no uncertain terms) to murder in the highest degree. Nestlé in particular became the focus of the global campaign and the campaign did not mince words. One documentary, simply entitled "The Baby Killer" (originally released in 1974 and translated into multiple languages), made explicit the connection between the products of formula companies and infant death. A Swiss activist group retitled the documentary even more explicitly as 'Nestlé kills babies' [미]. The campaign was at least in part successful due to the easy identification of an irredeemable villain, the formula industry, and the facile association of their marketing practices with a reprehensible wrongdoing (namely, the wilful murder of babies).

The culmination of this global action against formula companies and their marketing tactics was the adoption of the International Code of Marketing of Breast-Milk Substitutes, approved by the World Health Assembly in 1981. Later reinforced by the Innocenti Declaration in 1990, -1 the Code was the international community's policy response to formula manufacturers' marketing practices in the developing world. The Code makes several recommendations, including instructing health care workers to promote breastfeeding. It clearly states the hazards associated with use of formula; banning the distribution of free formula samples to new mothers and the use of aggressive marketing practices; prohibiting the use of "milk nurses"; and prohibiting formula company salespersons from providing instruction on infant care to new mothers. Several countries acted immediately to implement the provisions of the Code, and formula companies came under significant pressure to conform to these international standards.

The clear villain in this global social justice framing is powerful multinational corporations with an economic incentive to push their products on unsuspecting low-income mothers in resource poor settings. This then becomes a larger issue of corporate ethics and also a story of inequality between the global North (where breast milk substitutes are not ideal, but are not deadly) and the global South, where it infant food source is a life or death issue. Given the inequality in outcomes faced by mothers in the global North and global South, policies to address this framing might be different between developing and developed countries. Policies in developing countries might include specific attention to international regulations on multinational corporations and their activities in LMICs, and particularly focus on how conditions of extreme poverty significantly raise the stakes in the breast versus bottle debate.

Human immunodeficiency virus (HIV) has further complicated the politics of breastfeeding in LMICs. Competition between the HIV community and child health community resulted in different standards for women in resource poor contexts. When HIV emerged as a major global epidemic in the early 2000s, tensions arose between advocates and physicians in the HIV community who recommended that HIV-positive women should not breastfeed and the child health community that recommended exclusive breastfeeding despite the small risk of HIV-infection [1ㄷ]. As many women living with HIV 
are only diagnosed following routine HIV testing during childbirth, with the expansion of services to prevent mother-to-child transmission during childbirth came recommendations in some acquired immunodeficiency syndrome (AIDS)-affected countries to formula feed rather than breastfeed. Early in the 2000s, UNICEF developed a programme to distribute free packs of formula in AIDS-affected countries [토]

Eventually, in a situation of inadequate sanitation, the scientific community agreed that the large risks of not exclusively breastfeeding on infant mortality outweighed the more moderate risk of HIV infection. Guidelines from WHO, UNICEF, and UNAIDS provided a reasonable framework within which to make choices on infant feeding appropriate to their socioeconomic circumstances. Formula feeding was recommended for HIV-infected women only when the practice would be "culturally acceptable" (i.e., not raise stigma regarding HIV status) and where it would be possible to prepare artificial milks hygienically. However, the guidelines stated that where formula feeding was not "acceptable, feasible, affordable, sustainable, and safe", HIV-infected women were recommended to breastfeed exclusively for the first few months. The statement was based on evidence from randomised trials that promotion of exclusive breastfeeding was estimated to prevent $13 \%$ of current child deaths whereas use of Nevirapine and replacement feeding would only prevent $2 \%$ of current global child deaths [16]. UNICEF eventually ended its formula programme, but not before significantly impeding breastfeeding promotion efforts in countries heavily affected by HIV [1드]. Representatives in developing countries raised concerns about whether there should be two sets of policies: one for developed countries and another for areas where clean water for formula feeding was scarce and if a $2 \%$ transmission rate of HIV was an acceptable trade-off.

These events are important on a broader scale in that they raise questions about the degree of risk posed by the failure to breastfeed exclusively in the global North versus the global South. In developed countries, breastfeeding is largely a luxury that is enjoyed by women of adequate means who can afford to take time off of work while bottle feeding is more concentrated in lower income groups. Moreover, the choice to bottle-feed in developed countries, while perhaps less than ideal, does not carry deadly consequences with it. However, in LMICs, where many households have inadequate access to improved water and sanitation, breastfeeding exclusively can literally be a matter of life and death. For example, UNICEF estimates that bottle-fed babies are as much as 25 times more likely to die in childhood than infants that are exclusively breastfed in the first 6 months of life (UNICEF 1990, cited in Carter 1995 [2]). Evidence of the more minor morbidities associated with bottle feeding in industrialised countries (as previously discussed) is too easily joined with these dire statistics from low-income countries. Putting these two very different breastfeeding contexts on the same scale diminishes the substantial difference in the magnitude of risk between these two settings. 
This situation puts the magnitude of risk implied by a failure to breastfeed exclusively in perspective globally and highlights the potentially skewed risk framing in late industrial "risk societies". Late industrial risk societies are marked by the continuous production of data to support or revise risk determinations leading to a "culture of fear". As Joan B. Wolf describes, 'everyday people are bombarded with advice about how to reduce their risk of everything from cancer to kidnapping' [] ]. That bottle feeding may be less risky for infant health than living in a polluted urban environment in a high income country, illustrates the successful risk framing of breastfeeding promotion campaigns at engendering fear more than promoting a rational benefit-to-risk assessment []].

Moreover, concerns have been raised by environmental activists about the potential for environmental pollution of breast milk, which theoretically could amount to a greater risk to infants than formula [17]. The relative balance in the degree of risk in different situations is rarely assessed or articulated in breastfeeding discussions.

While there is an unequal degree of risk from bottle feeding in low versus high income countries, some scholars suggest that the politics of breastfeeding in developed and in developing contexts are not clear cut. For instance, Van Esterik advocates to apply the same rubric in developed and developing countries to analyse how mothers' "choices" must be placed in context to historical events that have transformed the landscape of mothering for all women [3] . Placing an emphasis on the singularity of the problem in low-income countries also effaces the barriers to breastfeeding that are shared between women of the global North and of the global South, such as how to balance work and breastfeeding. The image of "third world" women homebound with ample time for suckling conflicts with research that shows women engage in informal and formal labour inside and outside the home in various developing country contexts. Furthermore, all women in low-income countries are assumed to have poor sanitation when in reality there is great diversity in the experiences and social conditions of these women (i.e., not all women in poor countries are poor). Instead, Van Esterik proposes that breastfeeding advocates examine four issues that influence infant feeding paradigms in any given national or local situation: poverty environments, empowerment of women, medicalisation of infant feeding, and the commoditisation of food []ㅡ].

In sum, the global human rights framing of the breastfeeding issue has perhaps been the single most successful breastfeeding promotion campaign. It constitutes a broader example of how a compelling causal story can bring policy attention and action to bear on an issue. The campaign achieved this success mainly through clear identification of a highly culpable villain (the profit seeking formula industry) that is easy to despise in the context of its victim (innocent, defenceless baby). The equation was simple and policy reform ensued. However, the corporate villain frame may oversimplify the complex factors driving women to bottle-feed in both developed and developing country contexts. 


\subsection{Critiques and Tensions in the Three Frames}

While each of the three frames - the mother's rights, children's rights, and global human rights frames - may offer compelling causal stories to advance breastfeeding policy on national and international agendas, the frames (and the policy communities that support them) also conflict with each other in unproductive ways. This is demonstrated by a recent landscape analysis of the global breastfeeding promotion efforts conducted by UNICEF [1] ]. This analysis found that a lack of cohesion over a common agenda with a shared vision of change is constraining the breastfeeding community's ability to influence policy makers and raise resources. Discussed below are several tensions (conflicts) in each of the above framings regarding the problem of low breastfeeding rates.

\subsubsection{Tension 1: Trade-offs Between Mothers' Rights and Children's Rights Frame}

The breastfeeding promotion literature is careful to recommend promoting policies that are "mothercentred" (See Alive and Thrive website: http:// aliveandthrive.orgL). However, breastfeeding promotion efforts have at times applied unsubtle social pressure to shame bottle-feeding women is applied to de-normalise bottle feeding by making formula difficult to access, banning pacifiers, and unequivocally advocating "breast is best". Taylor \& Wallace note that while studies often focus on maternal "guilt", shaming is a more appropriate descriptor of the emotions that women experience in their choice of breast over bottle [19] ]. They suggest that women should not be shamed for either choice. Proponents of a women's rights frame also suggest that breastfeeding promotion campaigns focus on promoting women's autonomy and on providing honest information on risks and benefits [20]. This, they propose, is preferable to reiterating scientific evidence that "breast is best", especially since this evidence in developed countries is considered to be of dubious quality [ㅇ] ], [1ㅜ] .

Efforts to normalise breast feeding may not be particularly harmful. However, an abundance of critical literature on the politics of breastfeeding has indicated the various ways in which the children's rights frame has led to overemphasis on the benefits of breastfeeding for children with little attention to balancing these benefits with the needs of mothers. This literature recognises that there are often trade-offs between what is best for mothers and what is best for babies (i.e., what is good for the goose is not always good for the gander).

This conflict is most evident in the US Department of Health and Human Services sponsored National Breastfeeding Awareness Campaign (NBAC). Their warning was that women who did not breastfeed put their babies at risk of various health problems; not to breastfeed was equated to a variety of risky 
practices, such as logrolling and riding a mechanical bull when pregnant. Based on messages of fear and blame, this social marketing campaign directed at mothers precipitated a wave of controversy and negative feedback [] ], [21] . This extreme version of the children's rights frame scapegoats women, and downplays the significant structural and social challenges women face in their capabilities to breastfeed.

More broadly and surprisingly neglectful of the breastfeeding issue overall, feminist literature centres around two visions of breastfeeding - with breastfeeding viewed from one standpoint as a reclamation of women's bodies and identities, and from the other as undermining women's equality by assigning a laborious, gender-specific task [4]], [2] , [7] .

This conflict epitomises the "central dilemma of feminism": on the one hand to minimise gender differences and foster androgyny between the sexes, and on the other to embrace and enhance gender difference and fight to remove constraints and transform patriarchal cultures [2]. Early liberal and Marxist feminist thinking on breastfeeding viewed breastfeeding as a barrier to gender equality, with breastfeeding naturalising the sexual division of labour within the home [4]. Milk substitutes levelled the playing field in the sexual division of labour by enabling men to attend to infants equally and women to participate more equally in the job market. However, recent feminist work has returned to the paternalistic, patronizing, and naturalising views on lactation in medical literature, which acts as a form of control over women, their bodies, and their reproductive choices.

Recent feminist work tries to resolve these two poles by turning the focus from individualised mother shaming tactics to how structural constraints inhibit women's capabilities to make informed, autonomous decisions [7]. For example, the American Academy of Pediatrics suggests exclusive breastfeeding for the baby's first six months and then complementary feeding accompanied by breastfeeding for at least the baby's first year or "as long as is mutually desired" [ㄹ2]. However, there is little logic in this recommendation. Most American workplaces offer either no paid maternity leave or 6-8 weeks only and lack support mechanisms for breastfeeding mothers. This situation makes it difficult for the majority of mothers to combine paid employment with lactation. The contradictions between the scientific advice and absence of institutional supports to realise this goal produces concerning dissonance.

In this way, the frames of maternal and child rights can and do collide. Policies that fail to take into account women's needs, and play on feelings of maternal guilt and shame, draw on fear and overstate the degree of risk and implore women to breastfeed without providing the necessary structural conditions to achieve this goal, can lead to dissonance and be counterproductive to efforts to promote breastfeeding. On the other hand, policies that are too pro-formula slip easily into a hegemonic bottlefeeding culture. 


\subsubsection{Tension 2: Different Standards for Developed and Developing Countries?}

The global human rights frame has been very successful at galvanising international attention and outrage towards formula companies. However, this successful framing of the issue has glossed over the important issue of why breast is so much better than formula in low-income country settings namely, the role of contaminated water in infant death. It is the unclean water used to mix the formula that is killing babies rather than the formula per se. If the goal is to improve child health and reduce child mortality (children's rights frame), then a priority must also be to attend to the conditions that give rise to contaminated drinking water and unsafe complementary feeding.

Furthermore, while it is true that "third world" women breastfeed much more than their "first world" counterparts, the global formula villain frame ignores the reality that this may be the result of a lack of alternatives [2]. What tends to be glossed over in overly naturalised discussions is that poor women in poor countries breastfeed largely out of necessity, because they have little other means by which to nourish their infants. In reality, women in low-income countries face similar challenges to breastfeeding to those of women in developed countries. Such challenges include sore nipples, flat or inverted nipples impeding adequate breastfeeding, time pressures, the need to work to survive, and exhaustion. Additional to this, many breastfeeding women in low-income countries are themselves malnourished. Studies in the child health frame report that malnourished women are able to produce adequate amounts of milk of reasonable quality to sufficiently breastfeed, but pay little attention to the cost to the mother's health. R. Kukla raises questions about the increased risk of osteoporosis from breastfeeding in developed countries [14 $]$. The risk of malnutrition and immune system weakness in malnourished breastfeeding women should be an additional consideration for a more balanced approach to the women's rights and children's rights frames. Appreciation of these challenges may also partially explain why exclusive breastfeeding rates and durations remain so low in much of the developing world where there are much higher rates and durations of mixed feeding (i.e., breastfeeding as well as feeding with water and foods). While "traditional practices" and overbearing mothers-in-law are frequently the scapegoats in these discussions, women's everyday realities and the simple inconvenience of breastfeeding may play an underappreciated role in the practice of supplementary breastfeeding.

Persistent promotion of exclusive breastfeeding without attention to everyday challenges to realise this ideal may undermine efforts to reach this goal. An alternative framing from this "breastfeed or bust" approach could be to take a "harm reduction" approach. This might include making bottled water and disposable bottles more widely available for women who do not breastfeed, much in the same way as clean needles are distributed to injection drug users. Thus, the means to bottle feed safely could be made more widely available in resource-poor settings where there is substandard sanitation. 
Additionally, single-use premixed formula that does not require mixing with water and that can be stored unopened without refrigeration could be sold. For women who wish to breastfeed exclusively, the provision of accurate information about the challenges that this might entail should support their decision.

Indeed, harm reduction approaches are in line with current language. This approach to breastfeeding could help to equalise the stakes in the breast versus bottle debate between high-income and lowincome settings, fostering women's autonomy and balancing the women's rights frame more evenly against the children's rights frame. A harm reduction approach can simultaneously advocate for changes in structural conditions impeding breastfeeding (e.g., workplace policies) while by acknowledging the role of everyday constraints on the practice of exclusive breastfeeding [6]

\subsection{Conclusion}

\section{Balancing women's rights, children's rights, and global human rights in making ethical and evidence-based breastfeeding policy recommendations.}

We began this chapter suggesting that policy issues and their solutions are driven by the concept of causal stories, i.e., the attribution of cause, blame, and responsibility on different actors. Stone reminds us that there are many strategies for pushing responsibility onto someone else [1]:

'Books and studies that catalyse public issues have a common structure to their argument. They claim that a condition formerly interpreted as accident is actually the result of human will, either indirectly (mechanical or inadvertent cause) or directly (intentional cause); or they show that a condition formerly interpreted as indirectly caused is actually pure intent'.

The breastfeeding community has drawn mainly on three causal stories or "issue frames" to advance breastfeeding promotion policy, namely, the women's rights frame, the children's rights frame, and the global human rights frame. The global human rights frame has been the most successful at painting a clear story of an intentional cause to the problem of declining breastfeeding rates and its dire consequences. By contrast, the children's rights frame has struggled because an overemphasis on children's rights implies an insensitivity or inattention to women's rights and needs. Portraying mothers as villains even if indirectly has not been a successful strategy for breastfeeding promotion and is likely to prompt negative reactions. Likewise, an overemphasis on the joys of breastfeeding and its association with women's rights that assigns blame to patriarchal norms ignores other feminist views that pro-breastfeeding culture shames women that cannot or will not breastfeed and inflates the benefits of breast over bottle. 
Moreover, the global human rights frame has simplistically outlined the problem as formula promotion by corporate villains without adequate attention to the broader underlying cause of "bottlebaby disease", which is unclean water and lack of sanitation. Reframing the issue of bottle feeding in developing countries that focusses attention on unsafe water would implicate a broader set of villains - governments, global development agencies, and perhaps even global capitalism that keeps poor countries poor. While this framing is likely to be less effective because the villain or cause is too diffuse, a harm reduction approach to breastfeeding could focus attention on how to bottle feed safely when breastfeeding is not an option.

A harm reduction approach to breastfeeding promotion suggests that advocates of breastfeeding should acknowledge that the risks of bottle feeding are not equivalent between developed and developing countries. They should more directly target the mechanisms in developing countries that are making babies sick. This includes increasing the availability of safer tools for replacement feeding and addressing feeding practices that undermine exclusive breastfeeding, such as giving water to breastfeeding infants not in the context of bottle feeding.

In sum, efforts at breastfeeding promotion are hindered by specific politics of breastfeeding policy. Recognition of the trade-offs in the different framings of the issue and identification of who is to blame can assist in developing more effective breastfeeding promotion campaigns.

\section{Key Points}

- Political discussions follow three frameworks - women's rights, children's rights and global human rights. Each requires clear policy focus if breastfeeding rates are to increase

- Mothers recognise the medical benefits for breastfeeding, but often face the reality of gender in-equality, patriarchal culture, work-place conflict and negative societal attitudes

- The focus for children's rights campaigners on the long-term health benefits of breastfeeding is often viewed as pressuring mothers who cannot, or choose not to breastfeed, likely prompting negative reactions 
- The success of global human rights campaigns in galvanising international attention and outrage towards formula companies as the main culprit for low breastfeeding rates is too simplistic

- The focus needs to shift towards a differentiated set of government led policies to create a more positive societal attitude to breastfeeding 


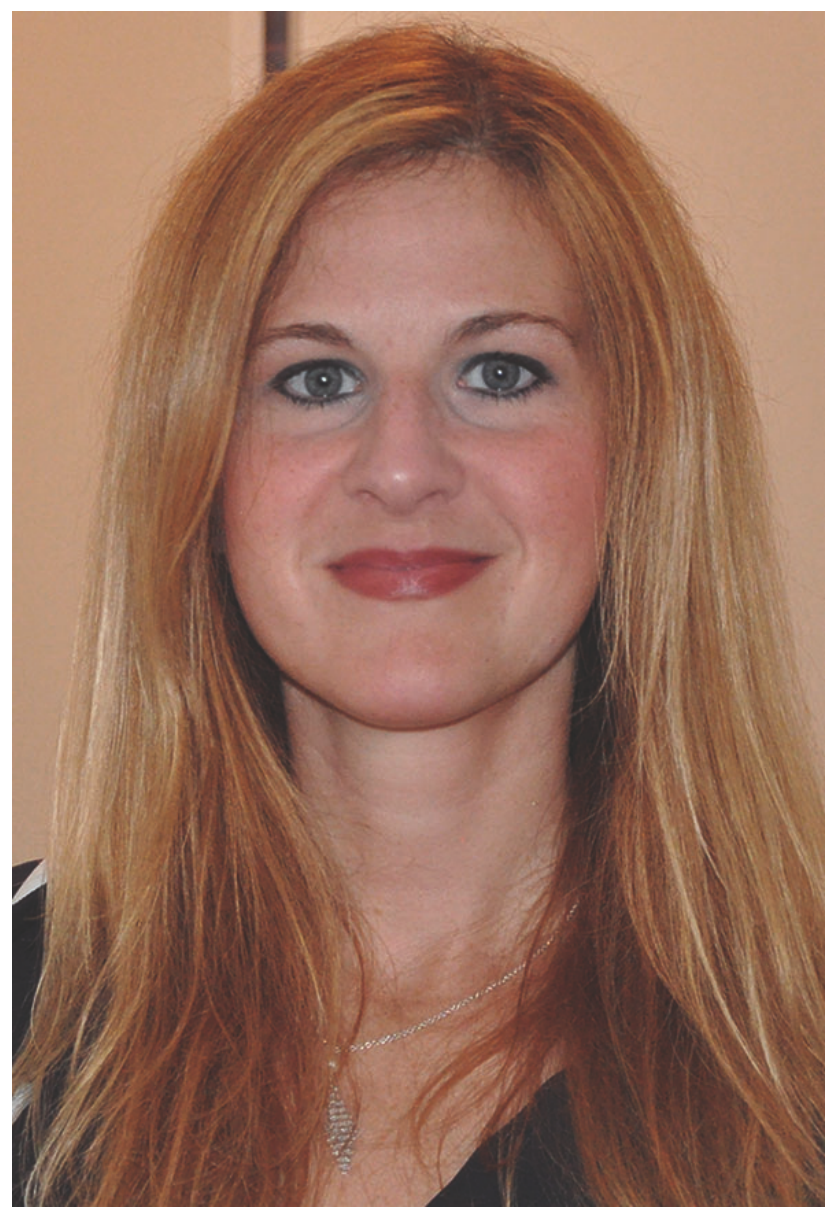

Ashley M. Fox, PhD, MA is an Assistant

Professor in the Department of Public Administration and Policy at the University at Albany, State University of New York. She received her PhD in Sociomedical Sciences from Columbia University in 2009. With a focus on sexual and reproductive and maternal and child health issues, her research focusses on the political aspects of public health, including the politics behind why some public health issues attract more government attention than others and the characteristics of policy issues that make them more or less contentious. She also examines how politics influences the policy making process and the direct and indirect effects of politics on variations in health status across populations.

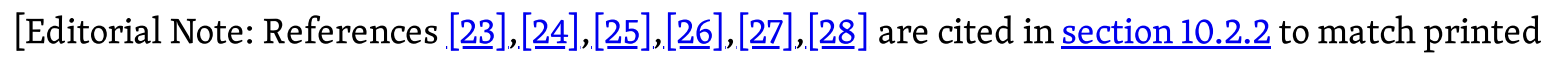
version] 


\section{Footnotes}

1. The Innocenti Declaration, which was drafted by WHO and UNICEF in 1990, restates WHO's recommendation for breastfeeding duration and calls upon member countries to promote a "breastfeeding culture" rather than a "bottle-feeding culture". The Declaration recommends creating national committees in member countries that bring together government agencies to coordinate their breastfeeding promotion efforts. It asks member nations to fully implement the International Code of Marketing of Breastmilk Substitutes to enact legislation promoting breastfeeding rights, to collect data and monitor national breastfeeding trends, and to promote the Baby-Friendly Hospital Initiative (BFHI). The BFHI was launched by UNICEF and WHO in 1991 and implements10 steps that can lead to an official designation as "baby-friendly". These include allowing women to initiate breastfeeding within the first 30 minutes of birth, "rooming in" between child and mother as soon as possible, not feeding babies formula or water, not using pacifiers, and training staff to provide support to breastfeeding mothers. According to UNICEF, some 15,000 hospitals in 134 countries have earned baby-friendly status since 1991.

\section{Citations}

1. Stone DA. Causal Stories and the Formation of Policy Agendas. Politic Sci Quart. 1989; 104: 281-300 
2. Carter P. Feminism, Breasts and Breastfeeding. New York, NY: St. Martin's Press; 1995

3. Van Esterik P. Beyond the Breast-Bottle Controversy. New Brunswick, NJ: Rutgers University Press; 1989 4. Blum LM. Mothers, Babies, and Breastfeeding in Late Capitalist America: The Shifting Contexts of Feminist Theory. Feminist Studies. 1993; 19(2): 291-311 트

5. Palmer G. The Politics of Breastfeeding: when Breasts are Bad for Business. London: Pinter and Martin Press; 2009들

6. Stearns CA. The Embodied Practices of Breastfeeding: Implications for Research and Policy, J Women Politics Policy. 2013; 34.4:359-370 7. Hausman BL. Breastfeeding, Rhetoric, and the Politics of Feminism. J Women Politics Policy. 2013; 34.4: 330-344

8. Wolf JB. Is Breast Really Best? Risk and Total Motherhood in the National Breastfeeding Awareness Campaign. J Health Politics Policy Law. 2007; 32(4): 595- 636ㅌ

9. Cook, Barnes A. Breastfeeding, Feminism and Political Theory. Dissertation. University of North Carolina. 2015. Available from https://cdr.lib.unc.edu/indexablecontent/uuid:cceaf9ce-8a22-4258be $04-48 \mathrm{clb} 4 \mathrm{bc} 5172$

10. Baumslag N, Michels DL. Milk, Money and Madness: the Culture and Politics of Breastfeeding. Westport, CT: Bergin \& Garvey; $1995_{\Perp}$ 
11. Stockholm Health Care Guide. Amning (Breastfeeding). 2011b 12. Fahlquist JN, Roeser S. Ethical Problems with Information on Infant Feeding in Developed Countries. Public Health Ethics. 2011; $4(2): 192-202$ ㅌ

13. Law J. The politics of Breastfeeding: Assessing Risk, Dividing Labor. Signs. 2000; 25(2): 407-450 ㅌ

14. Kukla R. Ethics and Ideology in Breastfeeding Advocacy Campaigns. Hypatia. 2006: 21(1): 157-180

15. Timberg C, Halperin D. Tinderbox: How the West Sparked the AIDS Epidemic and How the World Can Finally Overcome It. Reprint Edition. New York: Penguin Press; 2012 16. Coutsoudis A, Coovadia HM, Wilfert CM. HIV, infant feeding and more perils for poor people: new WHO guidelines encourage review of formula milk policies. Bull World Health Organ. 2008; 86: 210-214 트 17. Boswell-Penc M. Tainted Milk: Breastmilk, Feminisms and the Politics of Environmental Degradation. Albany, NY: State University of New York Press; 2006

18. UNICEF: Breastfeeding on the Wordwide Agenda 2013. Available at https://www.unicef.org/eapro/ breastfeeding_on_worldwide_agenda.pdf 19. Taylor EN, Wallace LE. For Shame: Feminism, Breastfeeding Advocacy, and Maternal Guilt. Hypatia. 2012; 27(1): 76-98 트 
20. Taylor EN. Leaving the Debate over Science Behind: Questions to Consider. J Women Politics Policy. 2013; 34.4: 384-392

21. Wolf JB. The Politics of Dissent. J Women Politics Policy. 2013; 34.4: $306-316$ ㅌ

22. American Academy of Pediatrics. Policy Statement: Breastfeeding and the Use of Human Milk. Pediatrics. 2005; 115: 496-506

23. UNICEF. Breastfeeding. 2011a. Available from http://www.unicef.org/nutrition/index_24 824.html

24. UNICEF. Breastfeeding. The Challenge. 2011b. Avail- able from http://www.unicef.org/programme/breast- feeding/challenge.htm

25. UK National Health Service (NHS). Breastfeeding your Baby. 2011a. Available from http://www.breastfeed- ing.nhs.uk/

26. UK National Health Service (NHS). Benefits of Breast- feeding. 2011b. Available from http://www.breastfeeding.nhs.uk/en/fe/page.asp?n1 = 2 ㅌ

27. Stockholm Health Care Guide. Mat och hälsa (Food and health). 2011a. Available from http://www.vard- guiden.se/Tema/Barn-ochforaldrar/Nyfoddoch-for- sta-aret/Mat-och-halsa/

28. La Leche League. (1996). Facts about Breastfeeding. Schaumburg, Ill: La Leche League International; $2006 \underline{ }$ 